\title{
PELATIHAN MEMBUAT WAYANG MILENIAL DENGAN MEDIA EVA FOAM UNTUK ANAK BERKESULITAN BELAJAR DI TALENTA JAKARTA
}

\author{
Julius Andi Nugroho ${ }^{1}$, Andreas ${ }^{2}$ \\ Universitas Tarumanagara \\ juliusn@fsrd.untar.ac.id
}

\begin{abstract}
Seni merupakan suatu karya yang selalu di sukai oleh banyak orang, kadangkala seni dapat juga di jadikan suatu karya yang bisa di perjual belikan, oleh karena itu seni membutuhkan kreativitas dan juga imajinasi untuk menambah wawasan dan ide-ide baru. Wayang yang biasanya terbuat dari kulit sapi dan dari pahatan kayu, kita membuat ide baru sehingga wayang dapat dibuat oleh anak berkesulitan belajar menggunakan media yang tidak berbahaya dan mudah di lakukan. Media tersebut adalah Eva foam sejenis karet padat dan mudah di bentuk dengan menggunakan gunting. Tujuan Pelatihan Membuat Wayang Milenial dapat meningkatkan motorik, kreativitas dan juga imajinasi Anak Berkesulitan Belajar, karena wayang milenial tidak ada keharusan membuat wayang berupa adat jawa, tetapi dia bebas membuat wayang sesuai keinginannya, seperti super hero, maskot film animasi, foto teman sehingga anak tersebut dapat berimajinasi dengan bebas. Metode perancangan yang digunakan menggunakan kwalitatif. Hasil dari pelatihan ini adalah melatih motorik anak berkesulitan belajar dan menambah wawasan baru, juga meningkatkan kreativitas. Pelatihan ini memancing ide-ide melalui imajinasi anak tersebut. Pembahasan yang telah dilakukan mengoreksi pada saat pelatihan dan apa saja yang perlu diperbaiki untuk pelatihan mendatang, karena pelatihan untuk anak berkesulitan belajar berbeda dengan anak pada umumnya.
\end{abstract}

Kata kunci: Wayang milenial, Eva foam, Kreativitas imajinasi, Anak Berkesulitan Belajar

\section{PENDAHULUAN}

Anak berkesulitan belajar merupakan terjemahan dari Bahasa Inggris "Learning Disability" yang berarti ketidak mampuan belajar dan kesulitan dalam belajar, seperti kesulitan mendengarkan(tidak mengerti yang telah di dengar), bercakap-cakap, membaca, menulis, menalar, dan dalam berhitung. Penyebab terjadinya Anak Berkesulitan Belajar yaitu sering mendapat perlakuan kasar, sering diolok-olok, tidak pernah dihargai, sering melihat kedua orang tuanya bertengkar. Keadaan seperti ini dapat menimbulkan kehilangan kepercayaan diri, sulit untuk memusatkan perhatian, cemas, gelisah, takut yang tidak beralasan. Hammill, et al., (1981) Anak Berkesulitan Belajar tidak pernah melihat dunia luar yang terjadi secara langsung, mereka hanya di rumah dan juga disekolah, dan hanya sebatas itu komunikasi mereka (temannya terbatas), mereka melihat dunia luar hanya media TV saja. Kreativitas juga dimiliki Anak berkesulitan belajar melalui imajinasi mereka, sayangnya kreativitas mereka hanya dibatasi di rumah dan di sekolah saja, padahal banyak kreativitas lain yang belum tergali oleh anak berkesulitan belajar. Kreatifitas dalam mengolah berbagai macam produk kini menjadi sebuah industri yang berkembang. Kreatifitas tidak hanya membuat sebuah produk menjadi fungsional atau ergonomis, tapi juga memiliki nilai jual yang lebih tinggi dari produk biasanya.

Wayang adalah suatu bentuk pertunjukan tradisional yang dihadirkan oleh seorang dalang, dengan menggunakan boneka atau 
Fakultas Seni Rupa dan Desain - Universitas Tarumangara

Julius Andi Nugroho, Andreas; Halaman 18-26

sejenisnya sebagai alat pertunjukan. seni pertunjukan ini berasal dari Indonesia dan berkembang pesat di pulau Jawa dan Bali. (Nur Fatin, 2017) Secara filosofis, pengertian wayang adalah bayangan, gambaran atau lukisan mengenai kehidupan alam semesta. Di dalam wayang digambarkan bukan hanya mengenai manusia, tapi kehidupan manusia dalam kaitannya dengan manusia lain, alam, dan Tuhan. Dalam kamus Bahasa Indonesia, Wayang merupakan boneka tiruan orang yang terbuat sari pahatan, kulit, atau kayu dan sebagainya yang dapat dimanfaatkan untuk memerankan tokoh dalam pertunjukan drama tradisional oleh dalang.(KBBI, 2016) Banyak jenis wayang yaitu wayang kulit, wayang bamboo, wayang kayu, wayang motekar dan wayang rumput.

Jenis-jenis wayang yaitu Wayang Kulit, Pada zaman milenial ini masyarakat terutama golongan anak-anak hingga remaja kurang peduli dengan wayang, ada beberapa pihak yang membuat pertunjukan wayang untuk generasi milenial. Sehingga wayang dibuat dengan lebih modern dan unik, seperti diberi pakaian yang di pakai sehari hari, baju bertema hip-hop atau baju yg sedang tren lainnya, atau wayang di buat dengan tokoh artis yang kita kenal. Kadang pertunjukan wayang juga dikolaborasikan dengan iringan musik hip-hop dan keroncong. Ada juga yang membuat wayang bertema marvel.
(Antarnesws, 2018) Ilustrasi adalah hasil visualisasi dari suatu tulisan dengan teknik menggambar, lukisan, fotografi, atau teknik seni rupa lainnya yang lebih menekankan hubungan subjek dengan tulisan yang dimaksud daripada bentuk. Tujuan ilustrasi adalah untuk menerangkan atau menghiasi suatu cerita, tulisan, puisi, atau informasi tertulis lainnya. Diharapkan dengan bantuan visual, tulisan tersebut lebih mudah dicerna. Secara terminologi ilustrasi merupakan suatu gambar yang memiliki fungsi sebagai sarana untuk menjelaskan suatu kejadian. (Soedarso,1990) Pelatihan Membuat Wayang Milenial Dengan Media Eva Foam dapat meningkatkan Kreativitas dan juga imajinasi anak berkesulitan belajar, karena wayang tersebut terbuat dari bahan yang berbeda pada umumnya dan juga tidak membatasi imajinasi si anak dari bentuk warna dan juga objek yang dipilih. Bahan utama adalah eva foam $3 \mathrm{~mm}$ atau semacam karet padat berwarna putih karena tidak menggunakan cuter dalam membentuk jadi aman bagi anak berkesulitan belajar, efa foam mudah dibentuk dengan menggunakan gunting biasa.

Permasalahannya adalah Anak Berkesulitan Belajar kurang mengenal dunia luar dan juga tidak mengetahui media-media baru, sehingga Yayasan Peduli Anak Spesial (YPAS) melalui Sekolah Talenta sebagai mitra 
Julius Andi Nugroho, Andreas ; Halaman 18-26

pengabdian kepada masyarakat FSRD

Universitas Tarumanagara meminta dosen dan juga mahasiswanya mengajarkan seniseni baru yang belum pernah di dapatkan di sekolah khusus. Pelatihan membuat wayang milenial dengan media eva foam dapat menambah pengetahuan anak berkesulitan belajar di bidang ilustrasi dan juga meningkatkan kreativitas.

Tujuan Pelatihan ini adalah membuka wawasan tentang dunia luar tentang wayang milenial baik di bidang ilustrasi, pewarnaan, pembentukan, ide-ide, kreativitas imajinasi dan juga melatih motorik tubuh mereka sehingga dapat seperti anak pada umumnya. Dengan banyaknya pelatihan-pelatihan membantu mengembangkan motorik mereka.

\section{METODE}

Metode perancangan Pelatihan Membuat Wayang Milenial Dengan Media Eva Foam Untuk Anak Berkesulitan Belajar Jakarta dengan cara :

1. Pengumpulan data permasalahan dengan menghubungi Hanna Kristyaji,S.E sebagai Kepala Sekolah Talenta dan ibu Arini Soewarno ketua YPAS. Setelah mengetahui masalahnya kami mencarikan solusi.

2. Mencari solusi dengan merancang sebuah Pelatihan dengan berdiskusi ke dosen dan mahasiswa lain, dan menayakan ide-ide yang akan di salurkan pada saat pelaksanaan berlangsung.

3. Memanfaatkan teknik Ilustrasi guna menghias Wayang milenial dengan melibatkan dosen llustrasi.

4. Pembuatan modul Pelatihan membuat wayang milenial dengan media eva foam yang dapat dibagikan ke anak berkesulitan belajar.

5. Pembuatan Video tetorial dan juga bahan ajar berupa power point cara membuat wayang milenial dengan media eva foam, agar mempermudah saat pelaksanaan serta dapat di jadikan panduan oleh siswa dan guru sekolah Talenta.

6. Pelatihan membuat wayang sudah disiapkan terlebih dahulu dengan mecoba karya-karya sederhana, sehingga dapat di peraktekan saat di lokasi.

7. Proses pelatihan akan berlokasi di Sekolah Talenta dengan alamat JI Perjuangan no 1B RT09/RW10 Kebon Jeruk, Jakarta Barat.

\section{HASIL DAN PEMBAHASAN}

Hasil dari pelatihan ini adalah melatih motorik anak berkesulitan belajar dengan banyaknya membuat karya-karya baru, karya anak berkesulitan belajar tidak dapat dibatasi melainkan diberi kebebasan sesuai keinginan anak tersebut, adapun yang ingin dicapai adalah anak berkesulitan belajar (disabilitas) mempunyai wawasan baru tentang kreativitas membuat wayang dan juga mencoba 
Fakultas Seni Rupa dan Desain - Universitas Tarumangara

Julius Andi Nugroho, Andreas ; Halaman 18-26

memancing ide-ide melalui imajinasi anak tersebut. Pembahasan yang telah dilakukan mengoreksi pada saat pelatihan dan apa saja yang perlu diperbaiki untuk pelatihan mendatang, karena pelatihan untuk anak berkesulitan belajar caranya berbeda dengan anak pada umumnya, dibutuhkan kesabaran dan juga penjelasan yang sangat mendetail.

\section{A. Tahap Pembuatan Wayang}

\section{Mempersiapkan Eva foam}

1. Pilih jenis Eva foam dengan ketebalan lebih kurang $3 \mathrm{~mm}$ berwarna warna putih.

2. Eva foam sifatnya lentur, kurang kuat, sehingga harus dilapis lem supaya lebih kaku. Untuk mempermudah pengerjaan pelapisan, potonglah evafoam sesuai dengan ukuran yang akan dibuat, misalnya ukuran kertas A3.

3. Proses memberi lapis eva foam dengan lem fox putih (lem kayu). menggunakan kuas lebar secara merata di ruang tebuka sampai kering, Setelah lem kering, berikan juga lapisan lem di sisi bagian belakang,

4. Biarkan kedua sisi lapisan lem kering. Pemberian 2 (dua) sisi lapisan lem yang kering membuat eva foam lebih kaku.

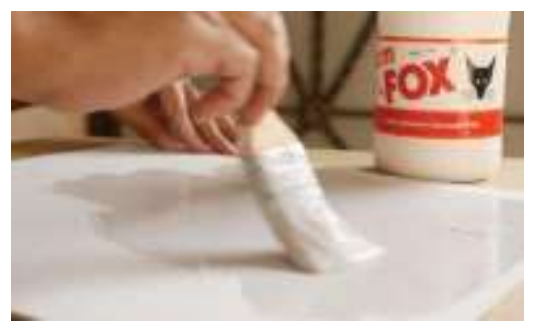

Gambar 1 : Melapisi bahan eva foam dengan lem putih/ lem fox di kedua sisinya, agar keras.

\section{Mempersiapkan desain gambar Wayang}

1. Buat gambar desain tokoh/karakter yang akan dibuat wayang pada lembar kertas gambar (usahakan tagak tebal), bisa dibuat ke ukuran sebenarnya dengan tinggi sekitar $40 \mathrm{~cm}$.

2. Karakter yang akan dibuat adalah karakter atau tokoh yang dikenali atau disukai. Lakukan penyederhanaan bentuk, sebaiknya yang tidak terlalu rumit, supaya prosesnya berjalan lancar.

3. Dalam membuat desain gambar, sebaiknya mulai dipertimbangkan gerakan yang dapat dilakukan tokoh tersebut. Terutama dalam penentuan bagian engsel gerak. Buatlah bagian yang akan bergerak dalam gambar yang terpisah.

4. Guntinglah gambar desain karton yang dibuat, hasil karton yang digunting memudahkan dalam proses tracing.

5. Letakkan potongan gambar pada eva foam dan lakukanlah tracing dengan menggunakan pensil atau bolpoint.

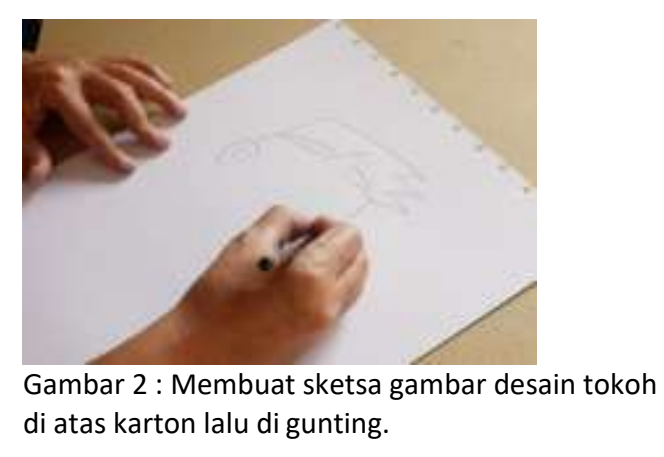


Fakultas Seni Rupa dan Desain - Universitas Tarumangara

Julius Andi Nugroho, Andreas ; Halaman 18-26

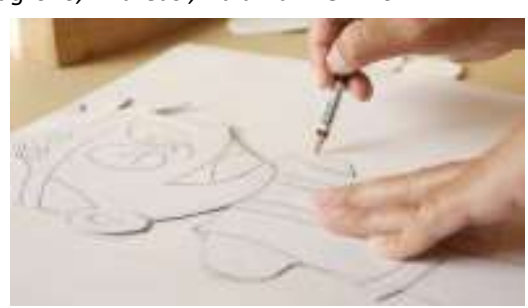

Gambar 3 : Melakukan tracing karakter diatas evafoam menggunakan pensil

\section{Menggunting Evafoam}

1 Potonglah eva foam sesuai gambar yang telah dibuat. Sebaiknya proses pemotongan menggunakan gunting. Selain mempertimbangkan faktor keamanan, penggunaan gunting akan lebih dapat menjangkau detail gambar.

2 Gunakan gunting yang kuat karena bahan yang akan digunting tebal dan kaku dan mungkin juga keras. Dampingi selama proses pengguntingan ini karena akan memerlukan waktu agak lama dan mempengaruhi bentuk akhir.

3 Lakukan pengguntingan secara bertahap, mulai bentuk secara garis besar kemudian, sambil melakukan penyesuaian antara alat yang digunakan dengan bahan yang di potong. Kemudian mulai mengikuti bentuk yang sudah di beri garis.

4 Lengkapi dengan detail gambar menggunakan pensil, lakukan hal yang sama di sisi sebaliknya, sehingga kedua sisi ada panduan gambarnya.

5 Hasil potongan eva foam, total ada 5 bagian, yaitu badan wayang, dua lengan atas, dan dua lengan bawah.

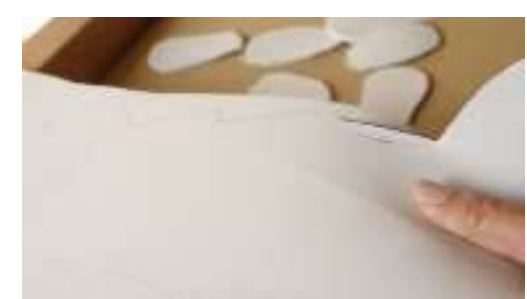

Gambar 4 : Menggunting gambar yang sudah di tracing di eva foam

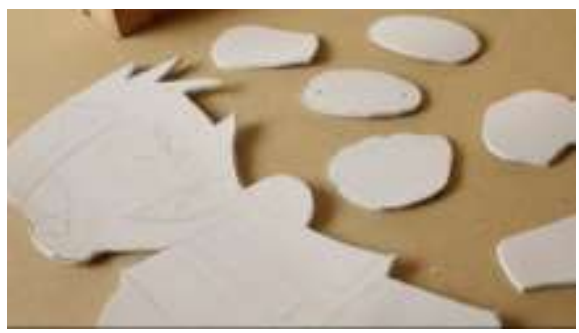

Gambar 5 : Guntingan eva foam ada 5 bagian, yaitu badan wayang, dua lengan atas, dan dua lengan bawah

\section{Mewarnai wayang}

1. Hasil potongan karakter yang sudah di buat, kemudian dilakukan pengecatan dengan menggunakan cat akrilik dengan menggunakan alat berupa kuas kecil.

2. Pengecatan tahap awal adalah memberikan warna dasar pada bidang sesuai dengan rencana gambar. Misalnya warna kulit muka dan tangan, warna baju atau celana dan lain-lain.

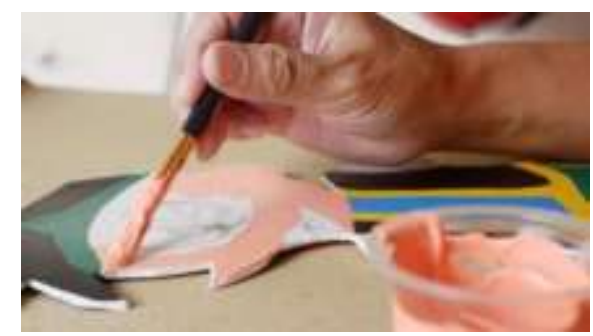

Gambar 6 : Eva foam dicat dengan cat akrilik menggunakan kuas kecil

\section{Membuat outline pada gambar}

1 Setelah dicat dengan akrilik dengan blok warna dasar, dilanjutkan membuat garis garis gambar yang tertutup cat, Pembuatan garis batas/ outline bertujuan memberikan 
Fakultas Seni Rupa dan Desain - Universitas Tarumangara

Julius Andi Nugroho, Andreas ; Halaman 18-26

batas antara bidang, supaya gambar karakter lebih menarik terutama bagian muka.

2 Garis dapat dibuat dengan menggunakan spidol permanen.

3 Atau dibuat dengan menggunakan kuas kecil dan cat hitam, jangan lupa mengecat pinggiran ketebalan eva foam agar rapi.

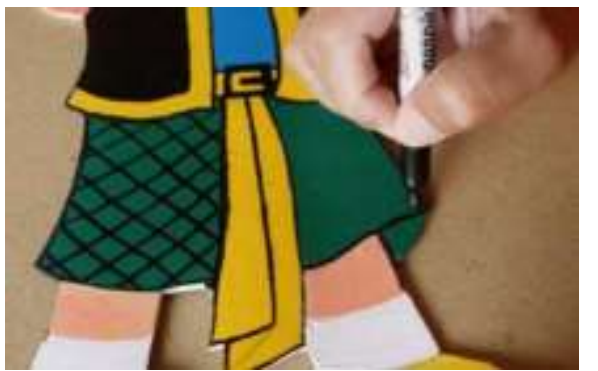

Gambar 7 : Setelah dicat dilanjutkan pembuatan outline/ garis dengan menggunakan spidol permanen

\section{Membuat dan memasang engsel sendi}

1 Membuat engsel pada prinsipnya seperti membuat sambungan untuk dua bagian namun pada titik sambungnya tidak permanen tetapi dapat bergerak atau digerakkan seperti engsel sebagai sumbu gerak.

2 Pemasangan engsel dengan membuat lubang bagian sendi dengan alat khusus. Besar lubang jangan sampai melebihi ukuran sedotan plastik.

3 Pasang potongan sedotan plastik pada lubang engsel dan satukan bangian yang terpisah sesuai dengan anatomi wayang yang telah dirancang, total ada empat persendian, yaitu dua bahu dan dua siku.
4 Sisa bahan sedotan yang menonjol dipanaskan dengan api hingga agak lembek, lalu ditekan dengan permukaan sisi gunting agar melebar. Setelah kedua ujung sedotan melebar dan mengeras maka sendi tidak akan lepas lagi.

5 Untuk tahap ini akan dibantu oleh asisten mahasiswa atau pembimbing lainnya.

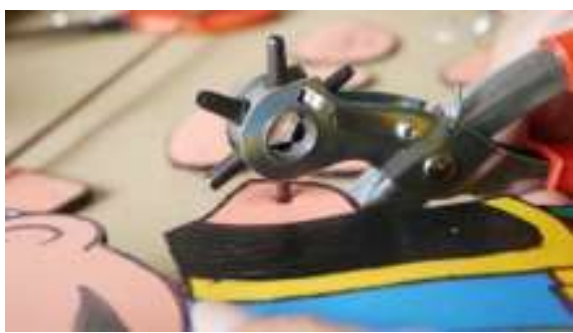

Gambar 8 : Melubangi bagian sendi dapat mengguakan obeng kecil

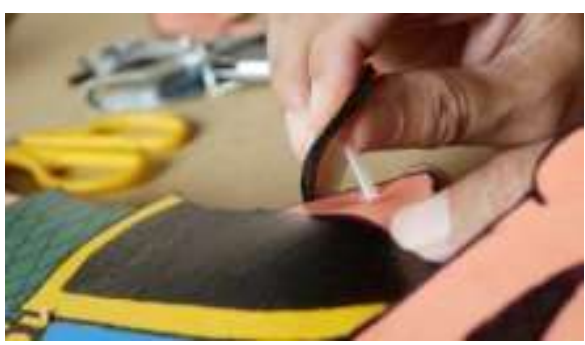

Gambar 9: Menyatukan bangian yang terpisah sesuai dengan anatomi wayang yang telah dirancang, total ada 4 persendian, yaitu dua bahu dan dua siku menggunakan sedotan kecil.

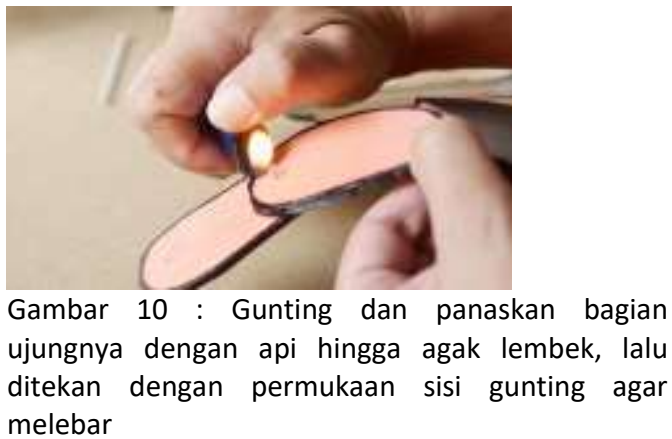

\section{Mempersiapkan dan memasang bilah bambu}

1. Untuk menentukan posisi peletakan bilah bambu pada bidang badan wayang, sebaiknya dilakukan simulasi terlebih dahulu dengan meletakkan bilah bambu 
Fakultas Seni Rupa dan Desain - Universitas Tarumangara

Julius Andi Nugroho, Andreas ; Halaman 18-26

pada posisi wayang. Posisi bilah harus lurus vertical (atas - bawah). Setelah posisinya di ketahui, buatlah tanda pada badan wayang yang akan dilubangi untuk mengikat antara wayang dengan bilah bambu,

2. Usahakan jalur bilah yang akan dipasang pada posisi yang baik, dapat sebagai menyangga badan wayang, dan tidak terlalu mengganggu desain tampilan wayang.

3. Berikan dua lubang kiri kanan yang akan mengikat bilah bagian yang telah ditandai, dengan menggunakan paku atau obeng. Perhatikan efektivitas jumlah lubang yang dibuat. Ukuran lubang cukup kecil saja supaya tidak mengganggu tampilan dan karena sifat evafoam yang lentur.

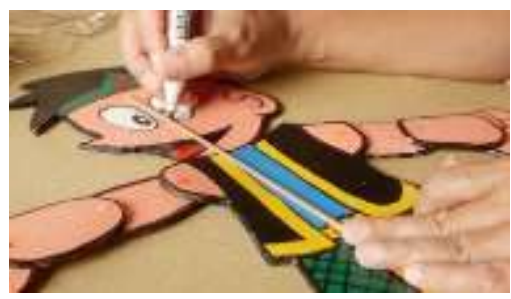

Gambar 11 : Buat tanda pada wayang yang akan dilubangi untuk mengikat bilah bamboo.

4. Siapkan beberapa kabel ties ukuran kecil. Usahakan menggunakan warna bening atau netral. Pasangkan kabel ties pada beberapa lubang di body wayang dalam posisi kait melingkar, tetapi jangan dieratkan dulu.

5. Setelah itu sisipkan bilah bambu penyangga utama pada lingkaran kabel ties, kemudian baru dieratkan talinya.

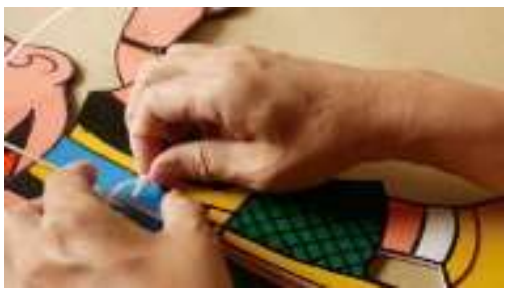

Gambar 12 : Setelah itu sisipkan bilah bambu pada lingkaran kabel ties, baru dieratkan

6. Langkah terakhir adalah memasang bilah bambu untuk mengerakkan tangan wayang. Ikatlah pada ujung bilah bambu penggerak dengan benang, sisa kan panjang benang kurang lebih $10 \mathrm{~cm}$.

7. Kemudian benang tersebut diikatkan juga pada sekitar telapak tangan wayang, (bagian ujung) dengan cara memberikan lubang pada bagian yang akan di ikat. Jangan terlalu dekat dengan tepi karena di khawatitkan akan merusak evafoam

8. Usahakan ada jarak antara ujung bambu dengan telapak tangan wayang agar gerakan lebih leluasa

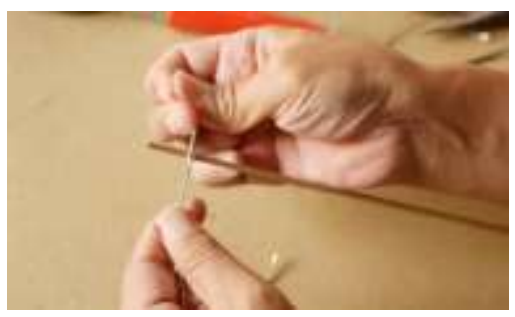

Gambar 13 : Memasang bambu untuk mengerakkan tangan wayang, ikat pada ujung bambu dengan benang

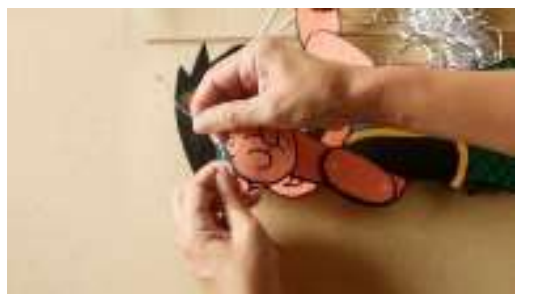

Gambar 14 : Lalu benang tersebut diikatkan juga pada sekitar telapak tangan wayang dengan di beri jarak $5 \mathrm{~cm}$ 


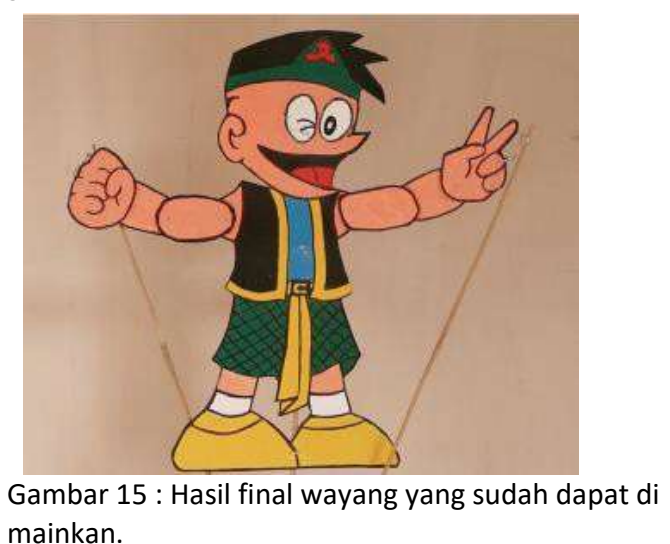

\section{SIMPULAN}

- Wayang milenial tidak dibatasi objek atau hanya tokoh-tokoh jawa, tetapi wayang milenial bebas menggunakan objek apa saja, baik dari film animasi, foto teman, atau keluarganya.

- Dengan adanya Pelatihan pembuatan wayang milenial dapat meningkatkan kreatifitas anak untuk berimajinas sehingga anak-anak dapat dengan mudah mengekpresikan apa yang diinginkan.

- Anak berkesulitan belajar ada hal yang dilarang demi keamanan, solusinya adalah menggunakan media eva foam mudah digunting.

- Manfaat dari video tetorial dapat digunakan sebagai bahan ajar di sekolah Talenta dan juga dapat dibagikan ke orang tuanya langsung, sehingga pada saat pengerjaan dapat di putar secara berulangulang.

- Bahan ajar berupa power point penting sekali bagi pengajar atau pembimbing anak berkesulitan belajar, sehingga dibuat bahan ajar yang sangat mudah dengan menggunakan banyak gambar dan juga foto-foto.

- Modul adalah panduan yang juga sangat penting dalam langkah-langkah menghasilkan wayang milenial yang menarik dan juga mudah,

- Sekolah Disabilitas atau sekolah khusus, membutuhkan banyak bantuan berupa ideide seni yang baru yang perlu di ajarkan agar meningkatkan motorik serta kreativitas anak tersebut.

Kekurangan dari pelatihan ini adalah perlu adanya pembimbing tambahan yang mengerti sifat anak tersebut, karena setiap anak mepunyai sifat yang berbeda-beda. tambahan intepretasi baru lagi.

\section{UCAPAN TERIMA KASIH}

Puji syukur kepada Tuhan Yang Maha Kuasa atas Rahmat dan KaruniaNya, kami dapat menyelesaikan pengabdian kepada masyarakat tentang Pelatihan Membuat Wayang Milenial Dengan Media Eva Foam untuk Anak Berkesulitan Belajar di Talenta Jakarta. Dalam kesempatan ini, kami mengucapkan terima kasih yang sebesarbesarnya kepada:

1. Jap Tji Beng, PhD., selaku Ketua Lembaga Penelitian dan Pengabdian kepada Masyarakat Universitas Tarumanagara. 
2. Kurnia Setiawan, S.Sn., M.Hum, selaku Dekan Fakultas Seni Rupa dan Desain Universitas Tarumanagara.

3. Hanna Krityaji, S.E Kepala Sekolah Talenta

4. Arini Ketua Yayasan peduli Anak Spesial

5.Rekan-rekan dosen dan juga mahasiswa DKV Fakultas Seni Rupa dan Desain Universitas Tarumanagara yang terlibat dalam Pengabdian Kepada Masyarakat ini. Akhir kata semoga kegiatan pengabdian kepada masyarakat ini dapat bermanfaat.

\section{DAFTAR PUSTAKA}

Adam Morioka, Color Design Workbook.

Direktorat PLB. (2004). Pedoman

Penyelenggaraan Pendidikan Terpadu /Inklusi

Direktorat PLB (2004). Menjadikan Lingkungan Inklusif, Ramah Terhadap Pembelajaran (LIRP), Jakarta: UNESCO Fatin, Nur. (2017). Pengertian Wayang serta Fungsi Dan Jenisnya. Seputar Pengertian.

Gusdiansyah, Rully, Teknik Cerdik Menggambar Wajah, (Jakarta: Gramedia), 2009 IDPN Indonesia. (2009) Merangkul Kamus Besar Bahasa Indonesia. (2016). wayang merupakan boneka tiruan orang
Antaranews. (2018). Pertunjukan Wayang Untuk Generasi Milenial. Antara News. Com.

Teori Albert H. Munsell

http://haichooodew.blogspot.com/2017/09/

media-pembelajaran-anak-

berkesulitan.html /1 Agustus 2018.

http://www.Idonline.org/ldbasics/whatisld/1

Agustus 2017.

https://ldaamerica.org/types-of-learning-

disabilities/1 Agustus 2017.

https://jagad.id/pengertian-ilustrasi-fungsi-

tujuan-jenis-dan-contoh/, Di akses

tanggal 20 Februari 2018

https://artsandculture.google.com/theme/Yw

LC8yxnsRUtJA, Di akses tanggal 1

Februari 2019

https://www.pelajaran.co.id/2018/04/penger

tian-wayang-fungsi-kandungan-dan-

jenis-jenis-wayang-lengkap.html

http://seputarpengertian.blogspot.com/2017

/05/pengertian-wayang-serta-fungsi-

dan-jenisnya.html?m=1 